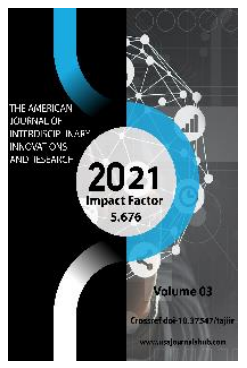

Journal Website: https://theamericanjou rnals.com/index.php/ta jiir

Copyright: Original content from this work may be used under the terms of the creative commons attributes 4.0 licence.

\section{Research Properties Of Cotton Knitted Fabrics Using Lycra}

Gulyaeva G. Kh.

Tashkent Institute Of Textile And Light Industry, Uzbekistan

Mukimov M. M.

Tashkent Institute Of Textile And Light Industry, Uzbekistan

Artikova M.

Tashkent Institute Of Textile And Light Industry, Uzbekistan

\title{
ABSTRACT
}

In the global production of knitwear, the leading place is taken by the issues of expanding the range of competitive products, the production of highly environmentally friendly goods from natural raw materials, the development of new types of raw materials and finishes, improving the quality of knitwear, and the development of resource-saving technologies. In developed countries "... special attention is paid to saturating the domestic market with products of its own production by $75-85 \%$ due to the textile industry and clothing production". Based on this, the development of a technology for the production of knitted products with high hygienic properties, increased dimensional stability and reduced cost through the effective use of raw materials and changes in the structure of weaves are important tasks.

\section{KEYWORDS}

Raw Materials, Cotton Yarn, Lycra, Linear Density.

\section{INTRODUCTION}

In world practice, in order to reduce material consumption, expand the range of knitted fabrics, there is a need to develop scientific foundations for improving the technology of knitted fabrics, developing mathematical dependencies of the effect of introducing additional elements into the structure of knitted fabrics, its properties and quality 
indicators, developing models for predicting properties and technological processes, with the aim of automating knitted fabric production processes, developing tasks optimization, their solution and development of the required scientific recommendations [13].

In order to increase the dimensional stability of knitted, keeping it hygienic properties, research opportunities to use a cotton yarn with a Lycra yarn instead of filament in the formulation of knitwear, developed knitted most common knitted stitches: plain (supreme), rib (ribana) and interlock using synthetic polyester yarns, cotton yarns and cotton yarns adding a lycra thread. It is known that lycra thread has unsurpassed elastic properties. The advantage of using, instead of lycra yarn filament as polyester, that the Lycra yarn is very thin and its content in the knitwear does not exceed $5 \%$. Furthermore, when used together with a Lycra yarn cotton yarn due to the structural features of Lycra thread as it rolls in cotton yarn and the finished web is not peeking at the web surface. This means that the synthetic lycra thread will not come into contact with the body when it is worn [4-5]. Experimental samples were obtained on the PROTTI-242 (Italy) flat knitting machine of 14 class. The raw materials used polyester yarn linear density 16,7teks (300 denier) x 4, cotton yarn linear density of 20 tex $\times 3$, and cotton yarn linear density of 20 tex $\times 3$ with the addition of Lycra yarn 7.8 tex (70 denier). I-III variants are produced by interlacing the smooth surface - one of the most common knitted fabrics in knitted fabrics. In this case, the I-variant is made of cotton yarn, the IIvariant is made of polyester yarn with a linear density of 33 tex $\times 2$, the III variant is made of cotton yarn with a linear density of 20 tex $x 3$ together with a lycra yarn with a linear density of 7.8 tex.

IV-VI variants are worked out by interlacing the eraser - the most common in knitwear production is a double weave. The IV variant is made of cotton yarn, the $\mathrm{V}$-variant is made of polyester yarn with a linear density of 33 tex $x$ 2 , the VI variant is made of cotton yarn with a linear density of 20 tex $\times 3$ together with a lycra yarn with a linear density of 7.8 tex.

VII-IX variants are developed by interlacing, imitating interlock, which is also very wide in knitting production. The VII variant is made of cotton yarn, the VIII variant is made of polyester yarn with a linear density of 33 tex $x$ 2 , the IX variant is made of cotton yarn with a linear density of 20 tex $x 3$ together with a lycra yarn with a linear density of 7.8 tex.

Figure 1 shows structures of the obtained variants of knitwear. 


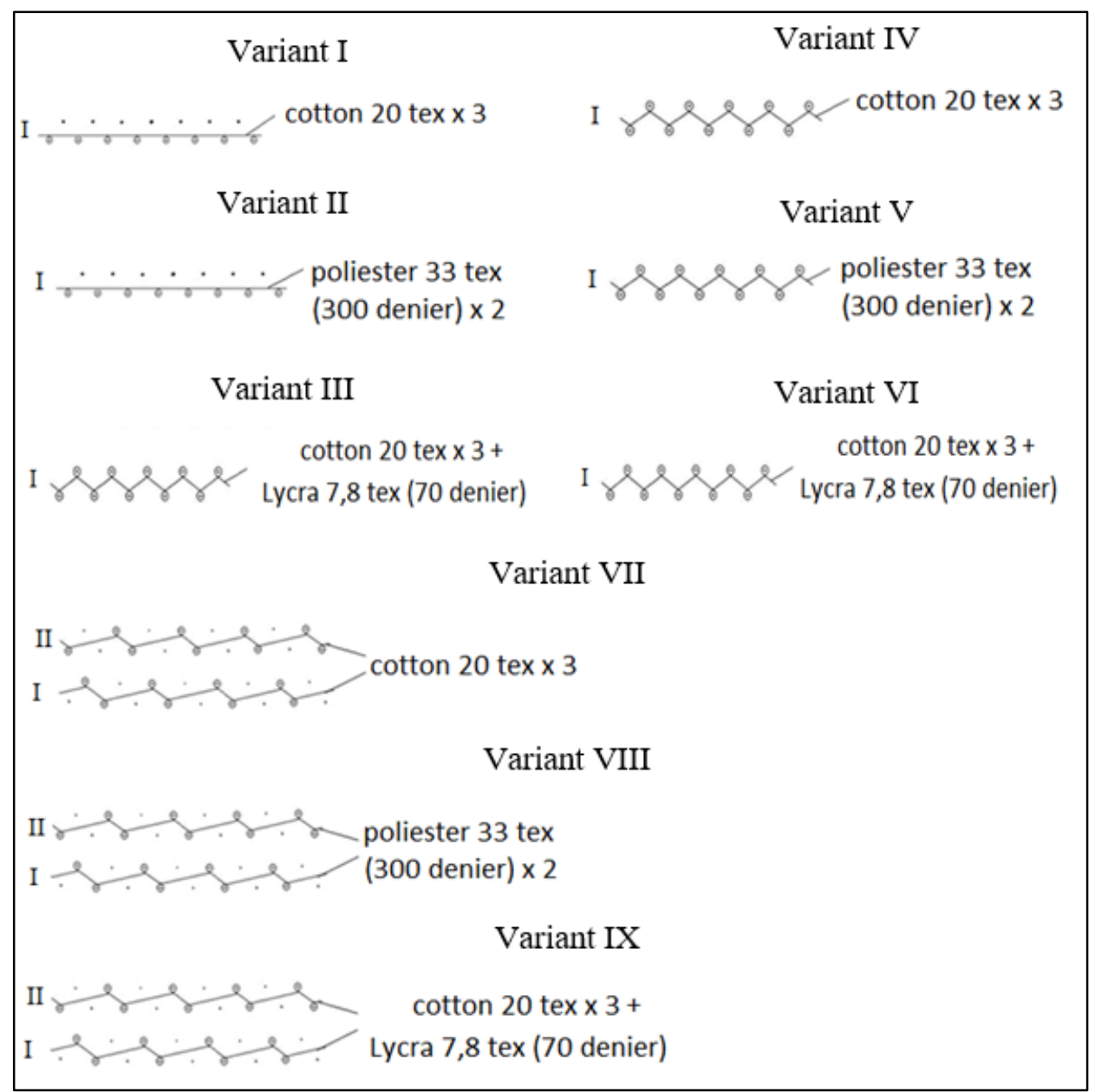

Fig. 1. Structure of combined knitted fabrics

The purpose of the study is to analyze the possibility of applying cotton yarn together with lycra yarn instead of synthetic polyester yarn. For this, it is necessary to compare the technological parameters and the physical and mechanical properties of knitted fabrics made from cotton yarn, polyester yarn and cotton yarn together with lycra thread. When developing experimental samples for more objective comparison, a yarn of approximately equal linear density approximating 60 tex was used.

\section{MATERIALS AND METHODS}

Technological parameters and physical and mechanical properties of the knitwear samples studied are determined by experimental methods in the accredited certification laboratory at TITLI CENTEX UZ, the results of measurements are given in Table. 1.

On the basis of the analysis of technological parameters, it should be noted that the loop pitch in samples made of polyester yarn and cotton yarn has similar values, and in samples made of cotton yarn together with lycra thread 
The American Journal of Interdisciplinary Innovations and Research (ISSN-2642-7478)

Published: October 20, 2021 | Pages: 5-14

Doi: https://doi.org/10.37547/tajiir/Volume03Issue10-02

the hinge pitch decreases, and consequently the density increases horizontally. The vertical density also increases in samples with a lycra filament. Thus, it can be argued that the inclusion of lycra yarn in knitwear, regardless of the type of weave, leads to an increase in the density of knitwear.

Table 1. Technological parameters and physical and mechanical properties of knitwear

\begin{tabular}{|c|c|c|c|c|c|c|c|c|c|c|c|c|c|c|c|}
\hline \multirow[b]{2}{*}{ 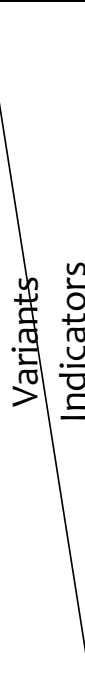 } & \multirow{2}{*}{ 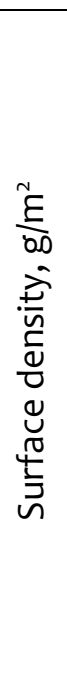 } & \multirow[b]{2}{*}{ 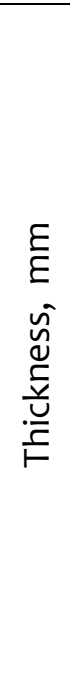 } & \multirow{2}{*}{ 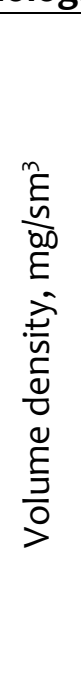 } & \multirow{2}{*}{ 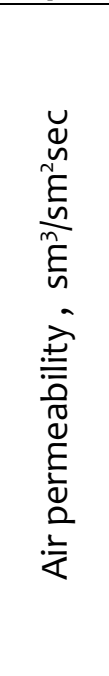 } & \multirow{2}{*}{ 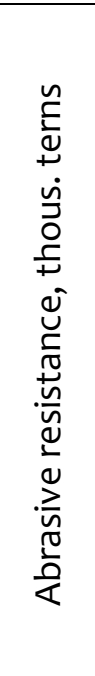 } & \multicolumn{2}{|c|}{$\begin{array}{c}\text { Break } \\
\text { force, } N\end{array}$} & \multicolumn{2}{|c|}{$\begin{array}{c}\text { Break } \\
\text { elongation } \\
, \%\end{array}$} & \multicolumn{2}{|c|}{$\begin{array}{c}\text { Perman } \\
\text { ent } \\
\text { deform } \\
\text { ation,\% }\end{array}$} & \multicolumn{2}{|c|}{$\begin{array}{c}\text { Revers } \\
\text { ible } \\
\text { defor } \\
\text { mation } \\
, \% \\
\end{array}$} & \multicolumn{2}{|c|}{$\begin{array}{c}\text { Shrinkag } \\
\text { e, \% }\end{array}$} \\
\hline & & & & & & $\frac{0}{\frac{0}{\pi}}$ & 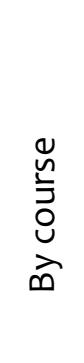 & $\frac{0}{\frac{0}{\pi}}$ & 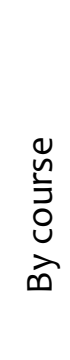 & $\frac{0}{\frac{0}{\pi}}$ & 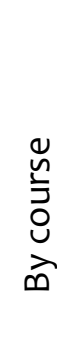 & $\frac{\frac{v}{\pi}}{\frac{\pi}{3}}$ & 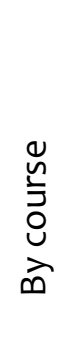 & $\frac{0}{\frac{1}{\pi}}$ & 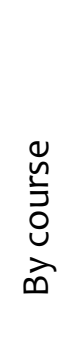 \\
\hline \multicolumn{16}{|c|}{ Plain } \\
\hline 1 & $\begin{array}{c}24 \\
1 \\
\end{array}$ & 0,8 & 301 & 188,6 & 23,8 & 239 & 123 & 56 & 138 & 32 & $\begin{array}{l}3 \\
8 \\
\end{array}$ & $\begin{array}{l}6 \\
8 \\
\end{array}$ & 62 & 13,3 & $\begin{array}{l}7 \\
3\end{array}$ \\
\hline 2 & $\begin{array}{c}32 \\
0\end{array}$ & $\begin{array}{c}0,7 \\
6 \\
\end{array}$ & 421 & 171,1 & 28,0 & 426 & 267 & 75 & 93 & 33 & 27 & $\begin{array}{l}7 \\
7 \\
\end{array}$ & 73 & $-3,3$ & $\begin{array}{l}6 \\
9\end{array}$ \\
\hline 3 & $\begin{array}{c}36 \\
5\end{array}$ & 1,15 & 317 & 50,9 & 26,7 & 369 & 214 & 122 & 182 & 16 & 18 & $\begin{array}{l}8 \\
4\end{array}$ & 82 & 7,7 & 8 \\
\hline \multicolumn{16}{|c|}{ Rib } \\
\hline 4 & $\begin{array}{c}39 \\
4\end{array}$ & $\begin{array}{c}1,4 \\
3\end{array}$ & 275 & 122,9 & 35,8 & 673 & 253 & 88 & 313 & 38 & 25 & $\begin{array}{l}6 \\
2\end{array}$ & 75 & 15,3 & $\begin{array}{l}- \\
6 \\
7\end{array}$ \\
\hline 5 & $\begin{array}{c}49 \\
6\end{array}$ & 1,4 & 354 & 130,5 & 54,2 & 917 & 470 & 79 & 189 & 6 & 15 & $\begin{array}{l}9 \\
4\end{array}$ & 85 & 4 & -2 \\
\hline 6 & $\begin{array}{c}42 \\
3\end{array}$ & 1,5 & 282 & 56,5 & 42,8 & 729 & 361 & 168 & 304 & 8 & 14 & $\begin{array}{l}9 \\
2 \\
\end{array}$ & 86 & 6,2 & 1,3 \\
\hline \multicolumn{16}{|c|}{ Interlock } \\
\hline 7 & $\begin{array}{c}50 \\
9\end{array}$ & $\begin{array}{c}1,4 \\
5\end{array}$ & 351 & 92,1 & 33,0 & 610 & 348 & 74 & 192 & 33 & 33 & $\begin{array}{l}6 \\
7\end{array}$ & 67 & 17 & $\begin{array}{l}- \\
2, \\
7\end{array}$ \\
\hline 8 & $\begin{array}{c}60 \\
3\end{array}$ & 1,5 & 402 & 104,7 & 57,1 & $\begin{array}{c}100 \\
6\end{array}$ & 618 & 99 & 197 & 11 & 24 & $\begin{array}{l}8 \\
9\end{array}$ & 76 & $-1,3$ & $\begin{array}{l}0 \\
9\end{array}$ \\
\hline 9 & $\begin{array}{c}58 \\
2\end{array}$ & $\begin{array}{c}1,8 \\
5\end{array}$ & 314 & 51,98 & 53,6 & 824 & 509 & 205 & 224 & 10 & 13 & $\begin{array}{l}9 \\
0\end{array}$ & 87 & 7,4 & 6 \\
\hline
\end{tabular}


The main physical and mechanical properties of knitted fabrics are the characteristics that determine their scope of use. The investigated samples of knitwear are designed for making outerwear. Therefore, the most important are such properties as air permeability, strength and form stability. The form-stability of knitted fabrics is characterized by extensibility, a fraction of reversible deformation and shrinkage. The physical and mechanical properties of the knitwear samples were tested experimentally using a standard procedure. The results are listed in Table 2.

When evaluating clothes from the hygienic point of view, air permeability of textile materials is very important, since it causes air ventilation under the clothes and largely determines the heat-protective properties of the material.

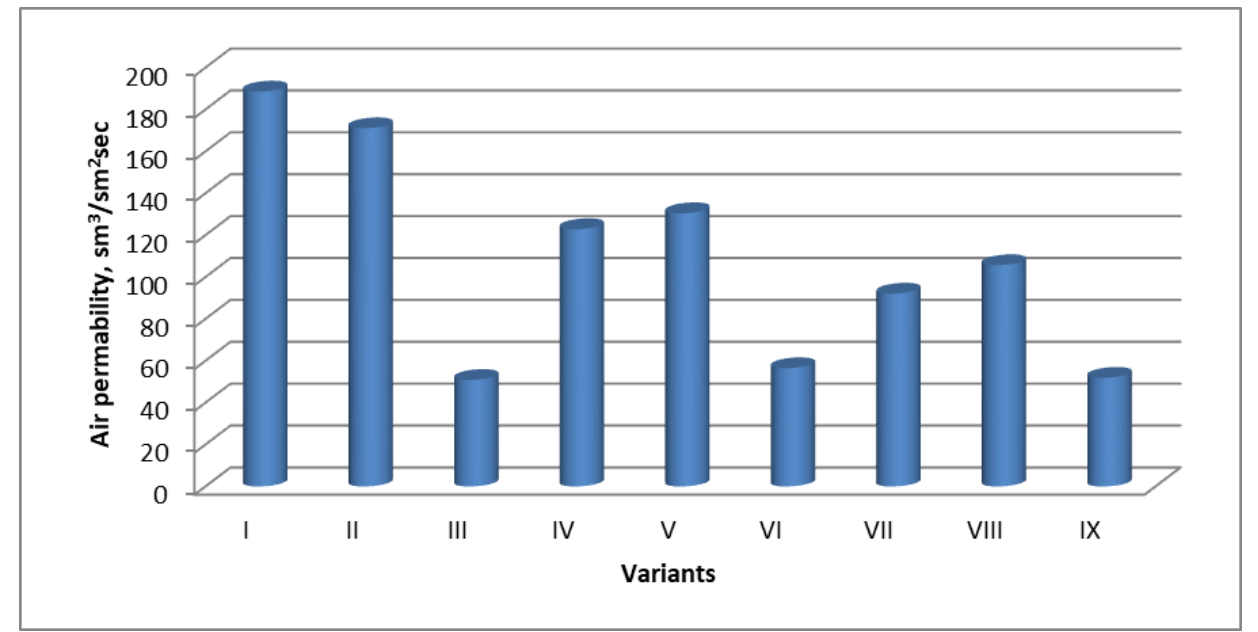

Fig. 2. Air permeability of knitted fabric with high shape retention properties

Top products should have sufficient thermal protection properties, i.e. Their air permeability should not be high. The norm for knitwear intended for upper garments produced on a flatfang machine is $40-90 \mathrm{~cm} 3 /$ $(\mathrm{cm} 2 \bullet \mathrm{s})$. It can be seen from the table that the inclusion of lycra thread in the knitwear makes it possible to significantly reduce air permeability and improve the heat-shielding properties of knitwear due to the increase in the thickness and density of knitwear. At the same time, in airless samples, the air permeability of the III variant, produced from cotton yarn with the addition of lycra filament, is $70 \%$ less than in the second variant, produced from polyester yarn, and $73 \%$, than the 1 st variant, produced from cotton yarn. In samples of the eraser, the air permeability of the VI variant, produced from cotton yarn with the addition of a lycra filament, is $56.7 \%$ less than for the $\mathrm{V}$ variant produced from polyester yarn, and by $54 \%$ than in the IV variant, produced from cotton yarn. In interlacing patterns, the air permeability of the IX variant, produced from cotton yarn with the addition of a lycra filament, is $50.3 \%$ less than for the VIII variant produced from polyester yarn, and by 43.5 in the VII variant produced from cotton yarn \%.

The index of abrasion resistance characterizes the stability of knitted fabrics to external mechanical action with surrounding objects. It is estimated that during the day a person does up to 30 thousand steps, that is about $20 \mathrm{~km}$. At the same time, he touches clothes with 
surrounding objects and clothes. The durability of knitted fabrics is strongly influenced by the strength of fiber fixation in the structure of the material, depending on the length of the fibers, the thickness and twist of the yarn, the interlacing, the density of the yarns, the length of the yarn in the knit loop, and the nature of the treatments that the materials undergo in the finishing operations. External friction of surrounding objects, causing wear of the material due to its abrasion, occurs at the points of actual contact of the contacting surfaces. The nature of the destruction of fibers in contacting areas is determined both by the structure of the material itself and by the type of the abrasive surface. The destruction of knitted fabrics during abrasion occurs as a result of the removal of short sections of fibers as they break up due to splitting, microcutting and less frequent removal of fibers from yarn without destroying them. In knitwear, the rupture of the yarn from abrasion leads to the descent of the loops, as a result of which the knitting of knitted fabrics is destroyed. Evaluation of the durability of knitted fabrics for abrasion is usually determined by the number of revolutions of the device before wiping the test specimen.

The indicators of abrasion resistance of knitted fabrics fluctuate within very wide limits, depending on the type of yarn, weave, density, etc. The abrasion resistance of the test specimens corresponds to the norms of abrasion resistance of knitted fabrics for upper products. The most resistant to abrasion were samples of knitwear, produced from polyester yarn. However, samples obtained from cotton yarn with lycra have values of abrasion resistance that are close to polyester samples. Breaking characteristics are important indicators $\urcorner$ accepted for a qualitative assessment of knitted fabrics, the tensile load norm are included in GOSTs and specifications for knitted fabrics. Breaking load of all samples of knitted fabrics in accordance with the norms of GOST 28554-90.

Knitted fabrics have a significantly higher stretchability than fabrics, and therefore a more mobile structure, sensitive even to small applied forces. The principle of the work of finishing equipment for knitted fabrics does not differ from the principles of the equipment intended for finishing fabrics. It is established that the main cause of large bumps is the excessive deformation of knitted fabrics in finishing operations.

Under the extensibility of knitwear is meant the ability to stretch it under the influence of the applied force. Stretch is characterized by an elongation of the test sample. The elongation is expressed in absolute or relative units. With a clamping length of $100 \mathrm{~mm}$, accepted for the testing of three knitted fabrics, absolute and relative values are the same. 


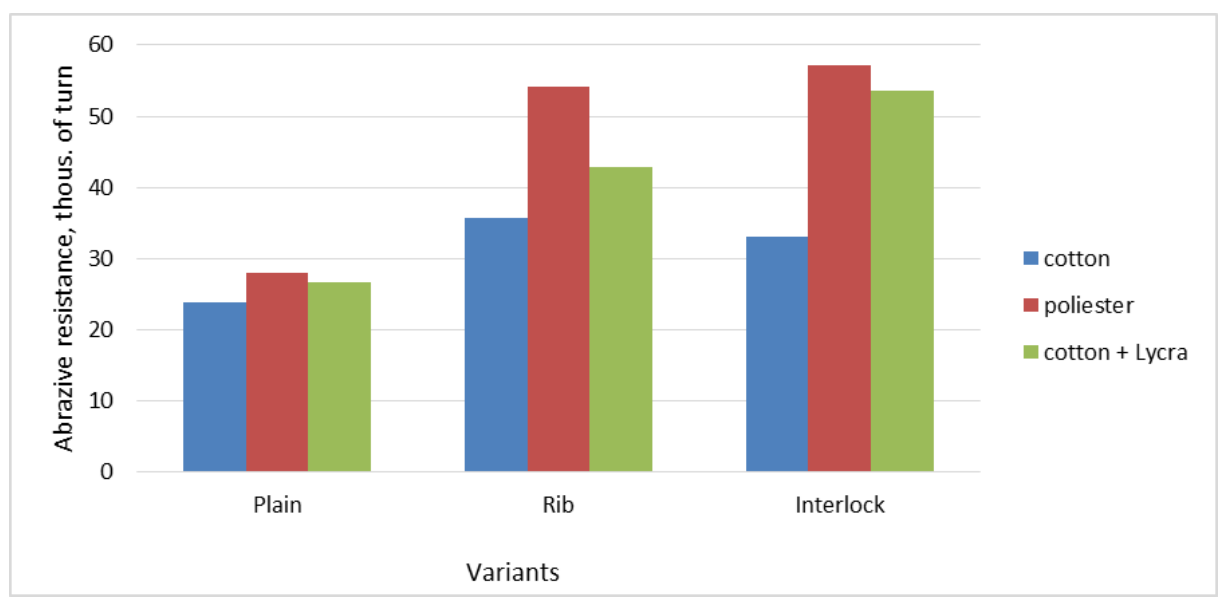

Fig. 3. Abrasive resistance

The indices of elongation at loads less than rupture are of particular importance for characterizing the operational properties of products made from a light-stretch fabric to reveal the limits of tapering in the design and construction.

The index of stretchability of knitted fabrics is in the range of $20-200 \%$. In view of this indicator, when designing products, appropriate amendments to the product dimensions are envisaged.

All knitted fabrics are divided into three groups depending on the index of elongation at a load of $6 \mathrm{~N}$. The first group includes cloths with an extensibility index of less than $40 \%$, to the second, with an extensibility index of 40 to $100 \%$ and to the third - more than $100 \%$.

\section{RESULTS AND DISCUSSION}

An analysis of the physical and mechanical properties of the knitwear variants studied shows that the extensibility of samples produced from cotton yarn with the addition of lycra thread is greater than in samples produced from cotton or polyester yarn. Here it should be noted that despite the property of stretching 7 times, the lycra thread has the property of restoring $100 \%$. How this property affects the knitted fabric, into which the lycra thread is tied, can be estimated from the index of reversible deformation of knitwear. Of course, an important indicator of the quality of knitted fabrics is the ability of a knitted fabric (article) to restore its original size and shape after wearing it. For the tested samples of combined knitwear, the proportion of reversible deformation was determined, which includes elastic deformation and the bulk of the elastic deformation, and the fraction of irreversible deformations including plastic deformation and part of the elastic deformation that did not succeed in manifesting within the "rest" Sample.

The fraction of reversible deformation is determined by the formula:

$$
\text { E_o }=(I \text { _-I_1 }) /\left(I+1-I \_0\right) \times 100 \% \text { (1) }
$$

Where lo is the initial length of the sample

L1- length of the sample after application of the load

L2 - length of the sample after "rest".

The fraction of irreversible deformation is determined by the formula:

$$
E_{-}{ }_{H}=100-\varepsilon_{0}(2)
$$


According to GOST 28882 "Cloth knitted for upper products. Norms of residual deformation »residual deformation of knitted The linen intended for top products should not exceed $15-20 \%$. The proportion of reversible deformation of knitwear samples produced from cotton yarn with the addition of Lycra is greater than that of samples made from cotton yarn and polyester.

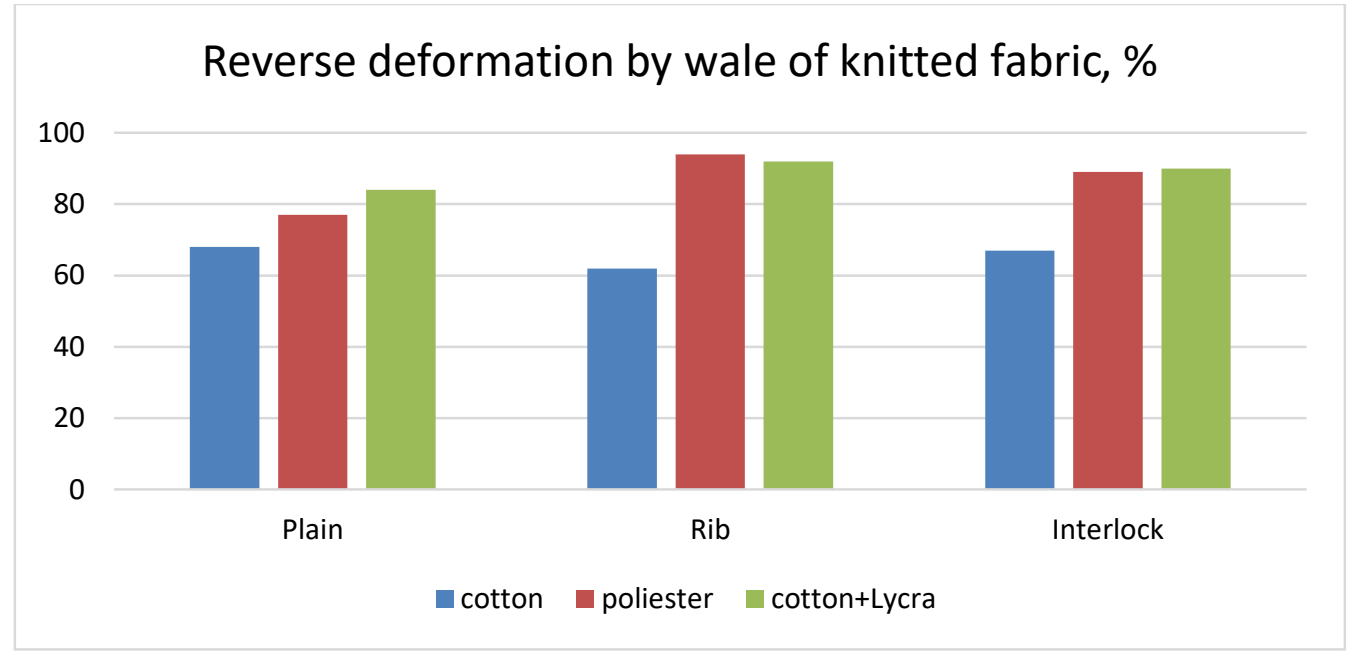

a

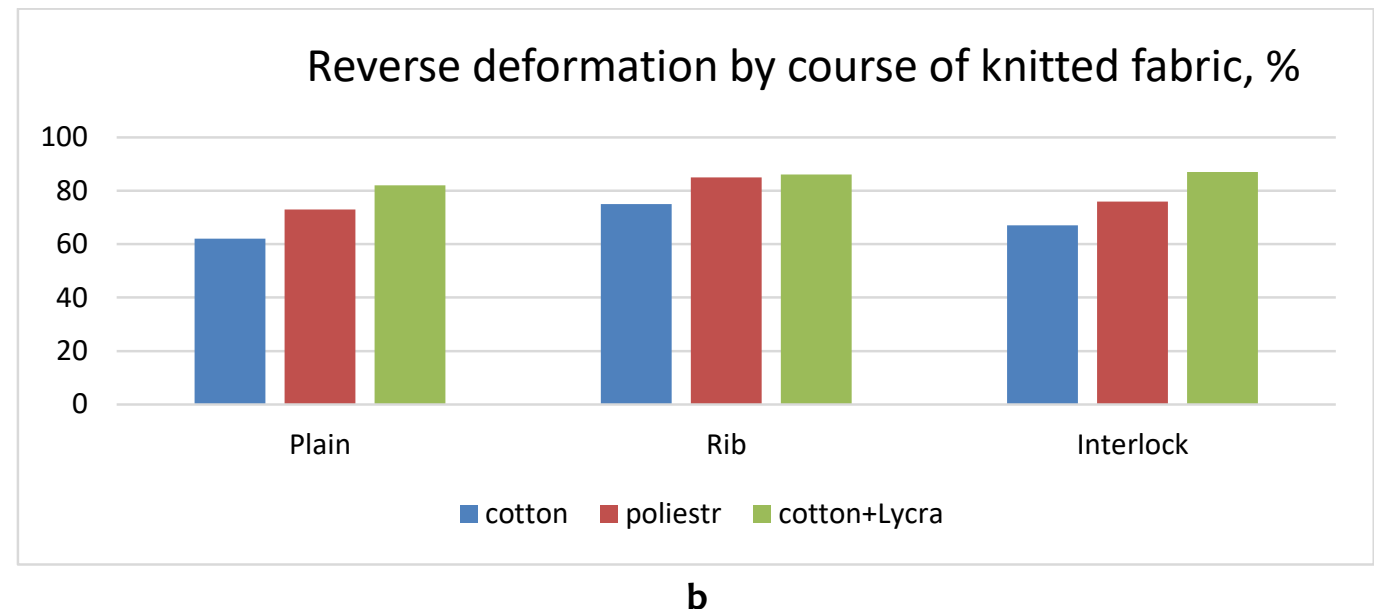

Fig. 5. Comparative histogram of reverse deformation percentage of knitted fabric

The proportion of reversible deformation of the knitted fabric of the weave, made of cotton yarn with the addition of Lycra (III variant), increased by $23.5 \%$ in length and by $32.2 \%$ in width, compared to knitted yarn made of cotton yarn (I-variant), and In comparison with the knitted fabric produced from polyester yarn (II variant) by $9.1 \%$ in length and $12.3 \%$ in width.
In the eraser specimens, the proportion of reversible deformation of knitwear produced from cotton yarn with the addition of Lycra (VI variant) increased by $34.2 \%$ in length and by $29.8 \%$ in width, compared to knitwear

produced from cotton yarn (IV) But in comparison with the knitted fabric produced from polyester yarn ( $V$-variant) by $1.2 \%$ in length and $14.5 \%$ in width. 
In the interlocking knitwear of interlock, the share of reversible deformation of knitwear produced from cotton yarn with addition of Lycra (IX variant) increased in comparison with knitwear produced from cotton yarn (VII variant) by $48.3 \%$ in length and by $14.7 \%$ in width , And in comparison with the knitted fabric produced from polyester yarn (VIII variant) by $2.1 \%$ in length and $1.2 \%$ in width.

Such high indices of the share of reversible deformation testify to the ability of the investigated knitwear samples, produced from cotton yarn with the use of lycra thread, to quickly take the original dimensions after stretching. Consequently, products made from them will quickly restore the original shape after wearing.

One of the most important properties of knitted fabrics during the operation of products is the preservation of their linear dimensions after the action of wet-heat treatments. When wetting, washing, dry cleaning, and under the influence of atmospheric moisture, the linear dimensions of knitwear vary, i.e. Shrinkage occurs. Shrinkage shrinkage, both during the manufacture of articles and when they are worn, may manifest itself to a greater or lesser extent depending on the modes of wet-heat treatment of the fabric in the production process, the fibrous composition, the structure and the stresses obtained by it during knitting.

The main reasons that cause shrinkage of knitwear are the reverse relaxation process and swelling of the fibers. In the process of knitting, internal stresses are created in the threads forming the loops. These strains occur even during the formation of yarns, then in knitting processes and especially when dyeing and finishing, where the knitwear is all the time stretched along the length in wet condition, and then fixed in stretched form in dryers. When trimmed on piles and calenders, jersey is often stretched instead of the required shrinkage along the length. Extraction in the process of finishing production influences the further behavior of the fabric in the manufacture of products and their wear, since in the wet state the fibers stretch particularly easily. Shrinkage in the conditions of wearing products depends on the type of detergent compositions and their effect on knitwear. Studies show that knitted fabric when soaked in soapy warm solution gives a greater shrinkage than when washing and boiling. With repeated soaking, washing and boiling, shrinkage continues, but with less intensity. Shrinkage indices and elastic properties of the fabric should be taken into account when designing knitwear. Changing the linear dimensions after wet processing (shrinkage or draw) must comply with standard GOST 26667 "Knitted fabrics for upper and glove products. Norms for measuring linear dimensions after wet processing". For combined knitwear, produced from cotton yarn in a flat-fleece machine, shrinkage rates are $6-8 \%$ in length, 8 $10 \%$ in width, and draw rates of no more than $5 \%$. Analysis of shrinkage indicators of the tested knitwear samples shows that all samples meet the standards established by standard. At the same time, the change in the linear dimensions of the knitwear produced from cotton yarn with the addition of a lacquer thread is larger than that of cotton yarn samples and less than for polyester yarn samples. 


\section{CONCLUSION}

Thus, as a result of the research work established that the application of cotton yarns with the addition of Lycra thread instead of filament in the formulation of knitted fabrics allows to obtain a knitted fabric with high quality characteristics that are not inferior jersey of polyester yarn, and with improved hygienic properties and attractive price, allows to increase the competitiveness of manufactured products, increase the share of processed local raw materials, and represent local producers in the international market of knitted products.

\section{REFERENCES}

1. Bera, M., Chattopadhay, R., \& Gupta, D. (2015). Effect of linear density of inlay yarns on the structural characteristics of knitted fabric tube and pressure generation on cylinder. The Journal of The Textile Institute, 106(1), 39-46.
2. Ališauskienè, D., Mikučioniené, D., \& Milašiute, L. (2013). Influence of inlay-yarn properties and insertion density on the compression properties of knitted orthopaedic supports. Fibres \& Textiles in Eastern Europe, (6 (102)), 74-78.

3. Umarova M.N., Turakhuzhaeva N.N. (2020). Study of the influence of the structure of knitted fabric on its properties. Universum: Technical sciences: electron. scientific. Zhurn, 2 p. (71). URL: http://7universum.com/ru/tech/archive/ite $\mathrm{m} / 8922$.

4. Gulyaeva G., Mukimov M. (2017). Technology of form-stable plush jersey production. Light industry technology, 1. pp. 80-83.

5. Mukimov M.M., Gulyaeva G.Kh. (2017). A method for increasing the dimensional stability of knitwear. J. "Problems of textiles", №3.-pp. 41-49. 